\title{
RAIDING PATTERN OF MIGRATORY ELEPHANTS IN A HUMAN DOMINATED LANDSCAPE IN NORTHERN BANGLADESH
}

\author{
Mohammad Shamsuddoha ${ }^{1^{*}}$ and M. Abdul Aziz \\ ${ }^{1}$ Department of Zoology, Jahangirnagar University, Bangladesh \\ ${ }^{2}$ Durrell Institute of Conservation and Ecology, University of Kent, UK \\ *Email: doha.captan@gmail.com
}

\begin{abstract}
This study addresses raiding patterns of migratory elephants in northern Bangladesh by raiding area visit, focus group discussions (FGDs), key informant interviews and other secondary sources. During the study period, over 750 acres of cropland, at least 228 houses, death of 8 people and serious injury to 26 people was caused due to elephant raiding; additionally, 2 elephants also died due to conflict. We observed that migratory herds cross the surrounded border fence from India to Bangladesh through at least 61 entry points, raided for a week or more in 54 border villages then moved back. The group sizes of raiding elephants were highly biased to large groups and didn't vary seasonally. Raiding is elevated during the summer and autumn months, at night, and just before and after the paddy harvest season. It has been found that raiding incidents took place mainly around the crop fields and human settlements which were in close proximity to the border fence. Possible mitigation measures recommended specific for this transboundary region include improvement and preservation of remaining forest patches as a core elephant zone, eco-development initiatives, intensive awareness program, bilateral collaboration with Indian government towards conservation initiatives.
\end{abstract}

Key words: Elephant, Raiding, HEC, Temporal pattern, Spatial pattern.

\section{INTRODUCTION}

Elephants are considered as critically endangered in Bangladesh (IUCN Bangladesh 2015) because of their rapid decline of population as a consequence of habitat loss, fragmentation and the subsequent increase of human elephant conflict incidents (Sukumar 1989). Only 300-350 estimated wild Asian elephant existed throughout the country, of which approximately 200 are residents, and 100-150 are trans-boundary migrants (Islam $e t$ al. 2011). The presence of non-resident elephants in our study area (Sherpur and Jamalpur) coincides with paddy harvesting seasons, i.e., February- May and September-December (IUCN Bangladesh 2004, Islam et al. 2011). This area is geographically plain land where people usually live on cultivating paddy, which is easily accessible to elephant occupying in the hilly areas of India, that makes the raiding more intense. Increasing raiding incidents results increase in 
human elephant conflict (HEC) which develops negative mindset against the intruding elephants. A number of studies were carried out on the status and distribution (Islam 2006, Islam et al. 2011), ecology and HEC (Aziz 2002, Aziz et al. 2005, Shamsuddoha and Aziz 2014, Shamsuddoha 2015, Aziz et al. 2016), conservation management (IUCN Bangladesh 2004, 2011, Islam et al. 2011) and human attitude towards elephant conservation (Sarker and Roskaft 2010) in southeast regions of Bangladesh. Except several attempts of mitigating HEC in northern areas of Bangladesh, there is no comprehensive information on pattern of raiding and HEC. Hence this study could be useful in mitigation efforts that are currently implementing by conservation agencies. In this study an attempt has been made to understand the characteristics and patterns (temporal and spatial) of the raiding incidents and HEC for two years in the northern trans-boundary areas of Bangladesh.

\section{STUDY AREA}

The study was conducted in 4 Upazilas (a sort of sub-district) of Sherpur and Jamalpur district situated in the northern Bangladesh, namely Nalitabari, Jhenaigati, Sreebordi and Bakshigonj (Fig. 1). This area is bordered by Meghalaya district (India) to the north, Mymensingh District to the South-east and Jamalpur and Kurigram district to the west. Our study area supports lowland forest type among one of the most threatened habitat for wildlife in the country. In the study area, there are still small patches of degraded forest near the border, but the landscape is dominated by a farmland mosaic. The forest is dominated by Sal (Shorea robusta), admixtured with many tropical semi-evergreen and tropical deciduous trees, occurring in association with bamboo jungles and bushes. This area comprises 54 villages, comprising a major Muslim community along with Hindu and several ethnic communities (such as Garo, Hazong, Hodi, Mandi and Koch) with the overall density of about 803 per $\mathrm{km}^{2}$ (BBS 2011). People living in these areas have their own Folk-culture. Human settlements are very close to the border fence. Most households are predominately dependent on agriculture. The socio-economic situation hardly allows generating alternative sources of income in poor areas of the area. People directly depend on their harvest for survival. In general, men are the primary breadwinners, and women spend most of their time as homemakers. Besides paddy production, other significant production and exports are sugarcane, jute, betel leaf and handicrafts. Our study area is located in the tropical monsoon region and its climate is dominated by an annual wet and dry season with high temperature (average $27^{\circ} \mathrm{C}$ ), approximate rainfall of $2500-2000 \mathrm{~mm}$, average $75 \%$ of humidity and fairly marked seasonal variations. The topography of this low hilly area is very rugged and irregular with series of ridges.

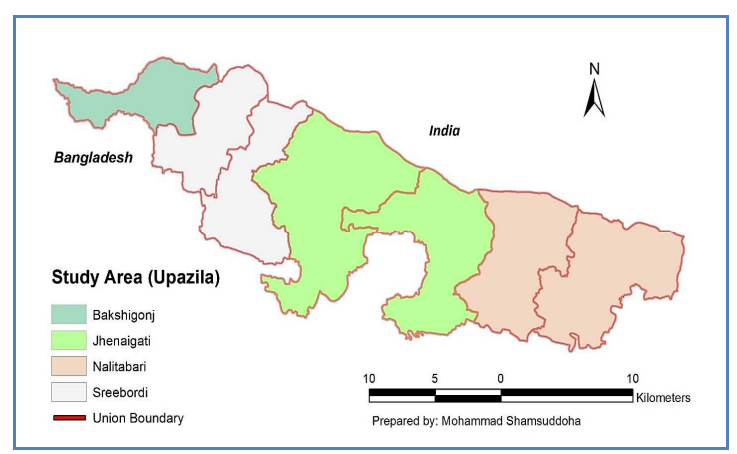

Fig. 1. Study area.

\section{MATERIALS AND METHODS}

Several data collection methods were followed for this study, such as, field visit on conflict areas, focus group discussion (FGD), key informant interviews and use of secondary data sources (Forest department and local NGO's data, Local and national newspaper etc.). We conducted 25 FGDs with a total of 376 participants and interviewed 94 key informants by using semistructured questionnaire from 54 villages covering 
all four upazilas. Major issues covered in FGDs and interviews included raiding pattern, HEC localities, intensity of damage of crops and houses, livestock loss, injuries and death of both humans and elephants. We have collected our data from the field between 2013 and 2014. We used GARMIN eTrex Global Positioning System (GPS) to record elephant movement locations, point data for entry points, HEC areas and raiding incidents. GPS collected data was imported on to the Geographic Information System in ArcGIS 10.3.1 and Google Earth to delineate raiding incidents. Microsoft excel software has been used for data analysis.

\section{RESULTS AND DISCUSSION}

\section{Temporal pattern of raiding}

From the available data with FGD, FD and our field observation, we have incorporated data of raiding group sizes for all 75 incidents. It has been found that the family herds tend to raid most of the times $(88 \%, \mathrm{n}=66)$ than the solitary elephants $(12 \%, \mathrm{n}=9)$. Herds regularly visit the villages and raid crops, households throughout the year, where singles are less frequent (Fig. 2). The frequency of group raiding (Fig. 8) was higher in cropping season when compared to other times of the year. The average herd size was 18 with raiding group size ranging from 1 to 60 .

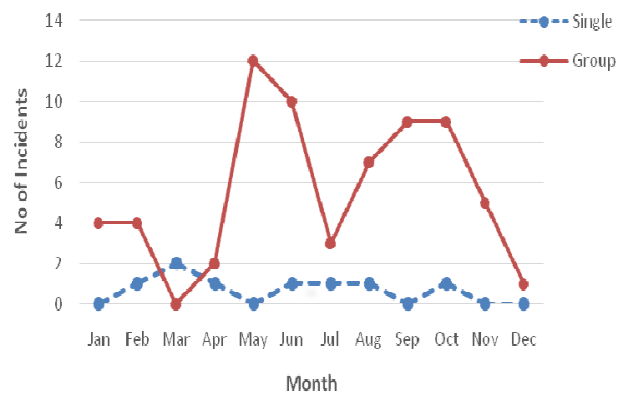

Fig. 2. Monthly variation of different elephant groups involved in crop raiding.
Elephants raid almost exclusively during night time $(87 \%)$, only in $13 \%$ of cases, raiding happened during daytime (Fig. 3). This might have some relation with local people's activity pattern. People in this area are active only during daytime, while elephants tend to raid less during this time period. On the other hand, during nighttime when people usually takes rest on their home and also due to the absence of visible light elephants raid exclusively.

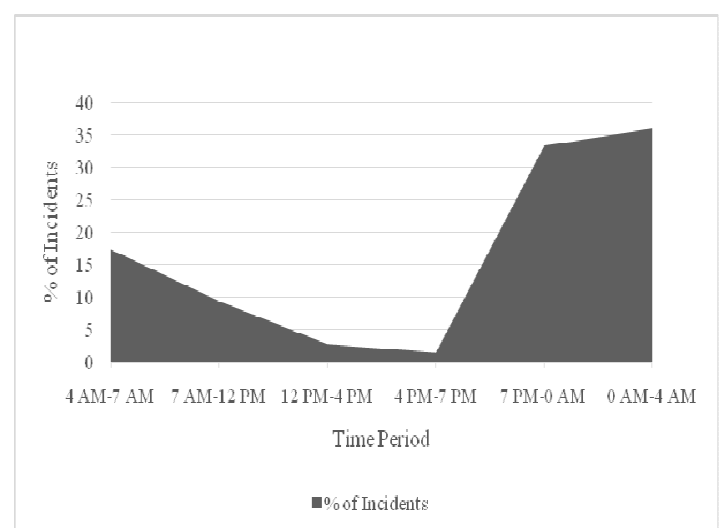

Fig. 3. Time distribution of raiding incidents.

We found a relation between raiding incidents of elephant and the paddy cropping pattern in this region. Elephants raid exclusively just before and after the harvesting, when the crops (paddy) are ripen and after the storing. Paddy ripens in different times of the year, so that harvesting of one may begin while the other is yet to reach maturity. There are four season for crop cultivation in this area, namely Aush, Aman, Boro and Short. Ripening, harvesting and storing of paddy are generally happened in between several clusters of months, May and June for Boro crop; August and September for Aush; October for Short crop; November, December, January for Aman crop. Only during these cluster of months, elephants damaged 507 acres of cropland in 45 raiding incidents, which is $68 \%$ of total (750 acres) cropland damage (Fig. 4). After harvesting and processing, crops stored in the houses. But soon 
after storing, raiders demolished 221 houses especially for stored crops, which is $97 \%$ of total $(n=228)$ house destruction in 31 raiding incidents during study period. Besides houses and properties, elephants also raid upon homestead plantation (7 incidents) during this time. As paddy cultivation is the main income source for the local people, they became engaged in depredation activities to protect their crop and it results into casualties in both end. Besides 2 elephant death, 8 people were died and 20 were injured due to depredation activities during those clusters of periods.

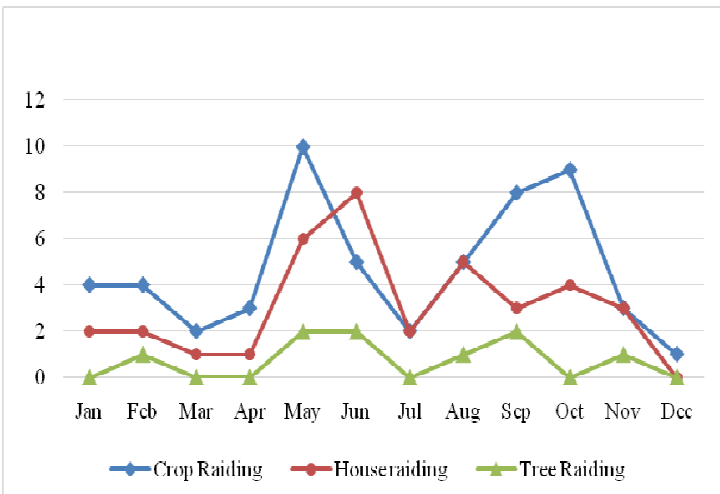

Fig. 4. Monthly variation of raiding incidents.

\section{Spatial pattern of raiding}

Our study area is completely separated by a 3layered strong fence from neighboring India, which is built by Indian government except some places of Dumurtala, Balijuri, Rangtia and Panihata villages of Bangladesh. Along with these open places $(n=6)$ elephants frequently use metal gates (which was built on fence, $n=44$ ) and 11 transboundary stream beds to trespass on Bangladeshi land in varied frequency (Fig. 5). Among the gates, maximum is on the boundary of Sreebordi (34\%, $\mathrm{n}=15)$, followed by Bakshigonj $(25 \%, \mathrm{n}=11)$, Nalitabari $(20 \%, \mathrm{n}=9)$ and Jhenaigati $(20 \%, n=9)$ Upazila. In terms of raiding frequency, among all the entry points, 11 points were highly used (more than 5 incidents of using those points) in trespassing, 17 were moderately used (2 to 4 incidents of use) and 33 were occasionally used (at least one incident of use) by the elephants. Whenever elephants came to raid the villages, we recorded which entry points it used, then determined the raiding frequency.

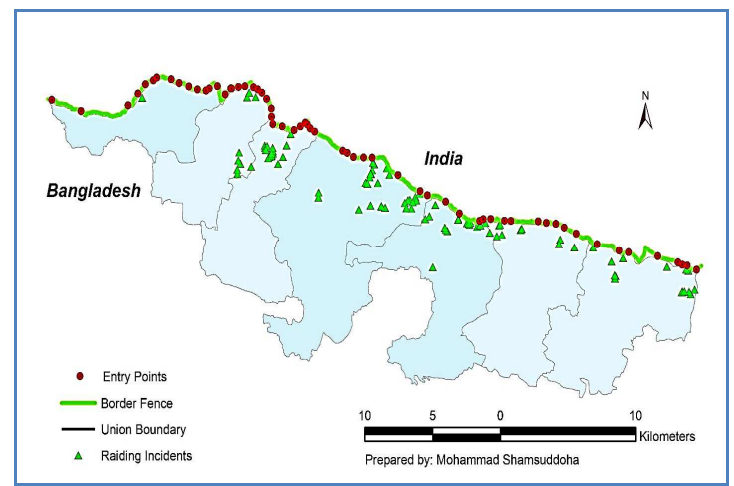

Fig. 5. Study area indicating border fence, entry point and recorded raiding incident locations.

Our spatial analysis on raiding data shows that $39 \%$ of the total raiding incident occurred within one kilometer from the border fence and $81 \%$ were within two kilometers and the raiding gradually decreases with the increase in distance (Fig. 6). No incidents were reported more than four kilometers from the border fence. This indicates that proximity to the border could be considered as one of the determinants of spatial distribution of raiding and HEC.

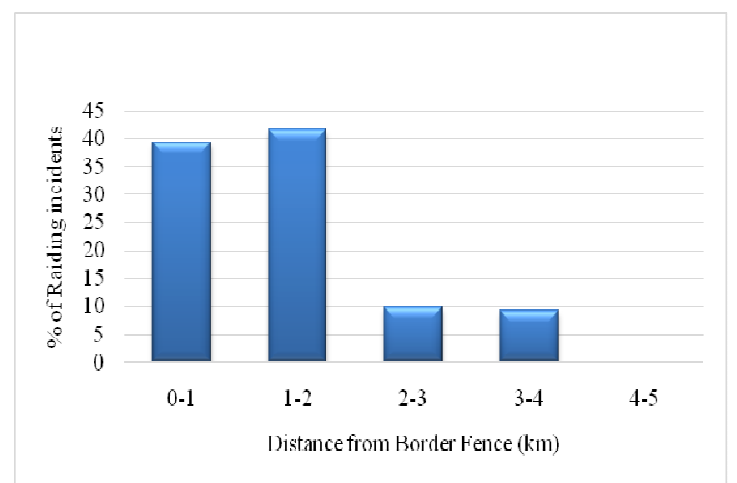

Fig. 6. Decrease in conflict incidents with the increase in distance from border fence.

ECOPRINT VOL 24, 2017 
Among the four Upazilas, maximum $37 \%$ of raiding incident occurred in Jhenaigati $(n=28)$ following Sreebordi (31\%, $\mathrm{n}=23)$, Nalitabari (27\%, $\mathrm{n}=20)$ and Bakshigonj (5\%, $\mathrm{n}=4)$. During raiding incidents, maximum amount of cropland destroyed by elephant groups in Bakshigonj and that was around 248 acres. Sreebordi is next in order, in which 208 acres of cropland destroyed, following Nalitabari (132 acres) and Jhenaigati (105 acres). In terms of house raiding, maximum 122 house demolished by the raiders in Nalitabari, following Sreebordi $\quad(n=55)$, Jhenaigati $\quad(n=35)$ and Bakshigonj $(n=16)$. In terms of Human or elephant casualties, no such incidents occurred in Bakshigonj during the study period. In Sreebordi, 4 people died and 3 injured and an elephant died due to the consequence of HEC. In Jhenaigati, 3 people died and 15 injured and in Nalitabari, 8 people injured and one died whereas one elephant died on the result of raiding (Fig. 7).

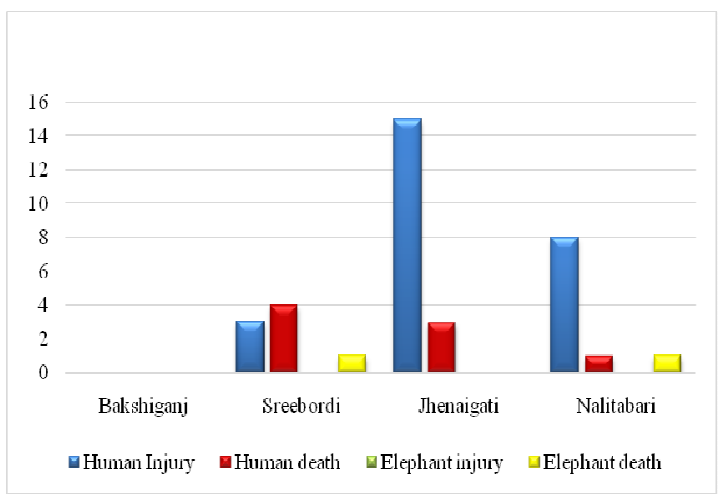

Fig. 7. Spatial distribution of Human and Elephant casualties.

Our observation shows that, in most of the cases $(75 \%, \mathrm{n}=56)$ elephant herd intruded into a village for once and engaged in raiding over cropland and settlements, then moved back through the fence. Only in $25 \%$ of cases $(n=19)$ elephants raiding took place in multiple villages by the same group at the same intrusion. This data also indicates the frequent back and forth raiding tendency which is more temporary in nature. On a more local scale, Balijuri village (11) faces maximum raiding over the period, following Gajni (9); Noukuchi (8); Jhulgao (7); Gandhigao and Halchati (6). These villages are more vulnerable to elephant raiding and in every year enumerable loss occurs due to elephant raid.

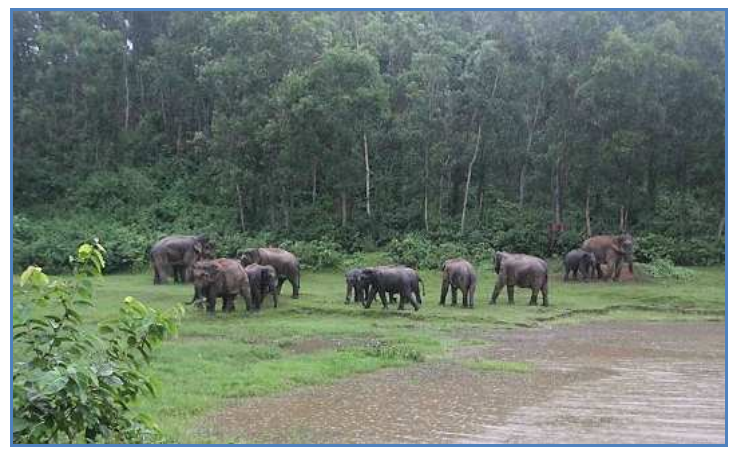

Fig. 8. Raiding of elephant herds in 2014 at Jhulgao.

The extent of raiding directly influences the economic aspects since conflict results into direct economic loss to the local people, which creates a problem without a solution. The present study reveals that damage to the properties and cropland is the most common feature of raiding by wild elephants. However, our data indicated paddy is the most raided crop by wild elephant throughout the year, especially intense during harvesting in northern Bangladesh. Engagement of local people in depredation activities cost for both elephant and human lives. Now some villagers minimized their cultivation and some completely stopped and shifted to acacia, rubber and beetle nut plantation, various vegetables (potato, chili, cassava, tomato etc.). People almost left planting banana and change cropping pattern by introducing elephant repellent attractive cash crops (jute, cotton, citrus etc.). It is a common practice in the study area to store grain in the house. Soon after harvesting, elephant find plenty of stored food inside the house, that tends to damage houses and properties as well as human lives. We observed that, due to traditional, cultural and religious attitudes towards 
wild animals make local people more tolerant towards elephant, despite damages to lives and properties. Unavailability of palatable crops and water source inside the forest, easily accessible crops in the field, sweet fragrance of ripen crops and seasonal fruits and also the seasonal movement behavior of migratory elephants are the main reasons behind raiding on villages. Habitat loss due to the destruction of forests is probably the greatest threat to the elephants in the study area. Due to the invasion of new settlements, forest covers shrinkages and wildlife populations along with elephants compressed gradually. We also found several threat issues which was similar to previous studies like disruption of migration routes due to development (IUCN Bangladesh 2004) and lack of awareness of highly growing human population (Islam et al. 2011). We also noticed that permanent fencing along with international border by India disrupts the regular movement of elephants between them and Bangladesh which was predicted earlier by Islam et al. (2011).

In Conclusion, we have identified an increase in raiding and HEC over the past decade as human settlements have increased within the area. To retain combatant situation, we have to identify systematic strategies to reduce elephant introduction and HEC. In addition to our recommendation for preventing further habitat loss and degradation, intensive awareness program, more systematic research on ecology, raiding behavior and conflict with human also need to be studied for peaceful co-existence. We also have to focus on eco-development initiatives, development of national elephant conservation action plan and bilateral collaboration with Indian government which can accelerate the conservational approaches for elephants. While these recommendations will not eliminate HEC, a reduction in raiding frequency on settlements which should greatly reduce human and elephant mortality.

\section{REFERENCES}

Aziz, M.A. 2002. Ecology of Asian Elephant, Elephas maximus and Its Interaction with Man in Chittagong and the Chittagong Hill Tracts. M.Sc. Thesis (unpublished), Department of Zoology, Jahangirnagar University, Savar, Dhaka, Bangladesh.

Aziz, M.A., M.M. Feeroz and A.F.M. Shahriar. 2005. Feeding movements of the Asian elephants in the northern side of the river Karnafuli in the Chittagong Hill-Tracts, Bangladesh. Bangladesh Journal of Life Science 17:51-58.

Aziz, M.A., M. Shamsuddoha, M. Maniruddin, H.M. Morshed, R. Sarker and M.A. Islam. 2016. Elephants confined to fence and farmers in northern Bangladesh: Implications for bilateral collaboration towards elephant conservation. Gajah 45:12-19.

BBS (Bangladesh Bureau of Statistics). 2011. Population and Housing Census 2011. Statistics and Informatics Division, Ministry of Planning, Government of the People's Republic of Bangladesh, Dhaka, Bangladesh.

Islam, M.A. 2006. Conservation of the Asian elephants in Bangladesh. Gajah 25:21-26.

Islam, M.A., S. Mohsanin, G.W. Chowdhury, S.U. Chowdhury, M.A. Aziz, M. Uddin, S. Saif, S. Chakma, R. Akter, I. Jahan and I. Azam. 2011. Current status of Asian elephants in Bangladesh. Gajah 35:21-24.

IUCN Bangladesh. 2004. Conservation of Asian Elephants in Bangladesh. (eds.) Sobhan, I., M.A. Aziz and N.A. Khan. IUCN-The World Conservation Union, Bangladesh Country office, Dhaka, Bangladesh.

IUCN Bangladesh. 2011. The Asian Elephants and Associated Human-Elephant Conflicts in South-Eastern Bangladesh. (eds.) Sobhan, I., M.A. Aziz and N.A. Khan. IUCN-The World Conservation Union, Bangladesh country office, Dhaka, Bangladesh.

ECOPRINT VOL 24, 2017 
IUCN Bangladesh. 2015. Red List of Bangladesh Volume 2: Mammals. IUCN, International Union for Conservation of Nature, Bangladesh Country Office, Dhaka, Bangladesh, pp. $\mathrm{xvi}+232$.

Sarker, A.H.M.R. and E. Røskaft. 2010. Human attitudes towards conservation of Asian elephants (Elephas maximus) in Bangladesh. International Jounral of Biodiversity and Conservation 2:316-327.

Shamsuddoha, M. and M.A. Aziz. 2014. Conservation status of the Asian elephant
(Elephas maximus) in the Chunati Wildlife Sanctuary of Bangladesh. Tigerpaper 41:6-13.

Shamsuddoha, M. 2015. Assessing Nature and Scale of HEC and Its Economic Impacts on Local Community in the Northern Transboundary Areas of Bangladesh. M.Sc. Thesis (Unpublished), Department of Zoology, Jahangirnagar University, Bangladesh.

Sukumar, R. 1989. The Asian Elephant: Ecology and Management. Cambridge University Press, Cambridge, UK. 